\title{
AS REVISTAS CIENTÍFICAS E A DISCIPLINARIZAÇÃO DOS ESTUDOS LINGUÍSTICOS NO BRASIL
}

\section{SCIENTIFIC JOURNALS AND THE DISCIPLINARIZATION OF LINGUISTIC STUDIES IN BRAZIL}

\author{
Caroline Mallmann Schneiders \\ Universidade Federal da Fronteira Sul, UFFS, Campus Cerro Largo, RS, Brasil
}

\begin{abstract}
Resumo: No presente estudo, refletimos sobre a importância das revistas científicas para a produção, circulação e legitimação do conhecimento linguístico no Brasil. Para nós, nas revistas, não há apenas a divulgação do conhecimento, mas também a relação entre o conhecimento e a comunidade científica, e esta contribui para a legitimação do saber entre seus pares. Nesta reflexão, mobilizamos a Revista Brasileira de Filologia, analisando a sua contribuição para a legitimação do domínio de saber da Linguística. Para tanto, filiamo-nos aos pressupostos da História das Ideias Linguísticas e da Análise de Discurso. Assim, partindo da relação entre circulação e legitimaçáo, a qual, por sua vez, instaura as filiaçôes de sentidos, entendemos que são, sobretudo, essas filiaçóes que fazem os saberes institucionalizarem-se e circularem em dada conjuntura sócio histórica e ideológica.
\end{abstract}

Palavras-Chave: Circulação; Legitimação; Conhecimento linguístico; Filiações de sentido.

Abstract: In this study, we reflect on the importance of scientific journals for the production, circulation and legitimation of linguistic knowledge in Brazil. For us, in such journals, there is not only knowledge dissemination, but also the relationship between knowledge and the scientific community, and this one contributes to the legitimation of knowledge among its peers. In this reflection, we studied the Revista Brasileira de Filologia, analyzing its contribution to the legitimation of Linguistics knowledge domain. Therefore, we followed the presuppositions of the History of Linguistic Ideas and Discourse Analysis. Thus, starting from the relationship between circulation and legitimation, this one which, in turn, establishes affiliations of senses, we understand, above all, that these affiliations make knowledge become institutionalized and circulate in a given socio-historical and ideological conjuncture.

Keywords: Circulation; Legitimation; Linguistic knowledge; Affiliations of sense. 


\section{Introdução}

Partindo do pressuposto de que "sem memória e sem projeto não há saber" (AUROUX, 1992, p. 11), entendemos a produção do conhecimento como um processo que deve ser compreendido a partir de sua constituiçáo, formulação e circulação. Nesse sentido, o nosso interesse neste estudo é refletir, especialmente, sobre a circulação do conhecimento linguístico em revistas acadêmicas/científicas. Consideramos que, ao refletirmos sobre a circulação, poderemos compreender, também, o modo de constituição e formulação em torno de determinados saberes, bem como destacar a importância das revistas científicas para a disciplinarização dos estudos linguísticos no Brasil.

Esse interesse deve-se ao fato de as revistas científicas, para nós, cumprirem "um papel fundamental tanto no processo de comunicação da ciência como na legitimação do conhecimento científico" (SCHNEIDERS, 2017, p. 2757). São, portanto, essenciais para a circulação do conhecimento, a partir das quais podemos observar as filiaçóes de sentidos que se estabelecem em determinadas condiçóes sócio históricas, visto que, quando certos saberes passam a constituir as práticas científicas, compreendemos uma (de) marcação de lugar em certas condições de produção.

Entendemos que as revistas científicas não visam apenas a divulgação do conhecimento, mas também a relação entre o conhecimento e a comunidade científica, e esta, por sua vez, contribui para a legitimação do saber entre seus pares. Para desenvolvermos essa reflexão, mobilizamos, como objeto de estudo, a Revista Brasileira de Filologia, uma revista representativa que circulou entre 1955 e 1961, no âmbito do contexto nacional brasileiro. Tendo em vista tal revista científica e a conjuntura sócio histórica de sua circulação, vimos compreendendo como essa materialidade contribui para a legitimação e circulação de determinados domínios de saber, como: da Filologia, da Linguística e da Dialetologia.

Nesse estudo em específico, o nosso interesse recai sobre os saberes que aí circulam vinculados ao domínio da Linguística, a fim de explicitar as filiaçóes teóricas e de sentidos que se constituem e contribuem para o processo de legitimação e disciplinarização da Linguística no Brasil. O desenvolvimento desse estudo está filiado aos pressupostos teóricos da História das Ideias Linguísticas e da Análise de Discurso de linha pecheuxtiana, tal como ambas desenvolvem-se no Brasil. Assim, partindo da relaçáo entre circulação e legitimaçáo, a qual, por sua vez, instaura as filiações teóricas e 
de sentidos, entendemos que são, sobretudo, essas filiaçôes que permitem aos saberes institucionalizarem-se em dada conjuntura sócio-histórica e ideológica.

\section{Circulaçáo, legitimaçáo e disciplinarizaçáo da Linguística no Brasil}

Ao refletirmos sobre a produção do conhecimento, consideramos que

é impossível pensar a ciência sem o sujeito e sem a história do conhecimento, porque ambos são constitutivos de nossa emancipaçâo intelectual. História nenhuma se faz sem sujeito, porque o sujeito na sua 'ponte' vem produzindo a história e sendo produzido por ela (SCHERER, 2008, p. 140).

Desse modo, ao problematizarmos a disciplinarização da Linguística no Brasil, devemos considerar que se trata de um processo que não envolve apenas uma regulamentação federal que determina a obrigatoriedade dessa disciplina em todos os cursos de licenciatura em Letras. Falar desse processo envolve, igualmente, a reflexão sobre o modo como esse domínio de saber institucionaliza-se no contexto brasileiro a partir de diferentes sujeitos e diferentes espaços institucionais. Ou seja, falar do disciplinar da Linguística, no Brasil, requer trabalhar tanto com o seu processo de disciplinarizaçáo quanto com o seu processo de institucionalização/legitimação.

Podemos dizer que o processo de disciplinarização da Linguística, no Brasil, foi lento, estando vinculado diretamente com a criação das primeiras universidades brasileiras, nos anos de 1930, as quais contaram com importantes estudiosos que se interessavam pela Linguística e também com professores visitantes franceses, marcando, inicialmente, uma filiaçáo com a Linguística europeia. Até 1962, data do decreto federal que torna a Linguística disciplina obrigatória nos cursos de Letras, esse domínio de saber não possuía um lugar institucional reconhecido diante dos estudos da linguagem. Isso fez com que a Linguística fosse praticada por um grupo restrito de estudiosos e divulgada de diversos modos (cf. ALTMAN, 2004) ${ }^{1}$. Dentre os estudiosos brasileiros que procuram divulgar e estabelecer o domínio da Linguística no Brasil, o principal foi Mattoso Câmara, considerado um dos primeiros linguistas brasileiros, o qual contribuiu não só para a introdução

\footnotetext{
${ }^{1}$ A Linguística era introduzida junto a outras disciplinas dos cursos de Letras, ou circulava em obras desse período, como as de Mattoso Câmara, e em revistas como a Revista Brasileira de Filologia.
} 
de ideias linguísticas no Brasil, mas também para a consolidação de uma história da linguística no/do Brasil.

Mattoso Câmara foi um pioneiro, porém, como ressalta Rodrigues (2005), ser pioneiro não significa ser o primeiro, pois, no Brasil, outros estudiosos, antecessores e contemporâneos de Mattoso Câmara, também dedicaram-se à introduçáo dos estudos científicos da linguagem. Devido a essa posição,

esteve praticamente isolado em grande parte de seu trabalho, experimentou a incompreensão e a hostilidade de seus colegas de formaçáo tradicional e espírito conservador, e viu-se tolhido no seu justo anseio de maior participação na vida universitária” (RODRIGUES, 2005, p. 24).

O estabelecimento da Linguística enquanto disciplina, via decreto federal, foi, porém, determinante para os estudiosos brasileiros legitimarem-se enquanto linguistas. A respeito dessa relação entre o estudioso e o campo disciplinar, Lagazzi-Rodrigues (2007, p. 13) entende que a "Linguística é legitimada por quem institui uma ciência, por quem pratica uma ciência, por quem ensina uma ciência, por quem divulga uma ciência”, mas considera que os espaços institucionais acadêmicos foram essenciais para a produção, expansão, circulação e representação dos estudos da e sobre a Linguística no Brasil.

Os espaços institucionais não são considerados como neutros quando tratamos da produçáo e circulaçáo do conhecimento, eles produzem, sobretudo, um efeito legitimador, já que são pelas relações institucionais que determinados saberes são legitimados e colocados em circulação, particularizando-os. Tal efeito contribui para que certos saberes e sentidos institucionalizam-se, a partir de determinadas condiçôes sócio-histórica e ideológicas (cf. SCHNEIDERS, 2014). Para Lagazzi-Rodrigues (2007), a "instituição", segundo um viés materialista, trata-se de uma organização discursiva que se origina de processos e percursos de institucionalização dos sentidos. Segundo a autora, a relação existente entre legitimidade e instituiçâao torna-se um modo de visualizar os processos de identificaçáa do sujeito, por meio dos quais se tem o reconhecimento produzido pela ideologia, o que seria um efeito fundante.

Sobre essa questáo da legitimação, a autora ainda destaca que é a legitimação que sustenta a relação existente entre a cientificidade e o lugar institucional, uma vez que a prática científica "se faz (em) um lugar insti- 
tucional" (LAGAZZI-RODRIGUES, 2002, p. 15). Tal lugar institucional, em nosso entendimento, somente será (de)marcado com o decreto federal tornando a Linguística como disciplina obrigatória dos cursos de Letras, em 1962. Antes disso, diante da "falta de lugar", a Linguística circulou de modo restrito e em um lugar secundário nos cursos de Letras.

Essa circulação restrita, digamos, no meio institucional dos cursos de Letras, não impediu o fato de a Linguística circular em outros espaços, como é o caso das revistas científicas ${ }^{2}$, e, em especial, de nosso objeto de estudo: a Revista Brasileira de Filologia, a qual é uma publicação vinculada à Livraria Acadêmica, editora importante da época, não sendo uma publicação filiada diretamente ao âmbito institucional da academia. Nesse sentido, entendemos que tais revistas irão cumprir um papel fundamental para a circulação e a legitimação da Linguística no Brasil, estabelecendo as relaçôes teóricas entre quem podia, ou não, publicar e circular junto a esse espaço. A circulação, para nós, é igualmente importante por possibilitar a observação dos saberes e das filiaçôes de sentidos que se estabelecem em dada conjuntura e condiçóes de produção. Conforme destaca Orlandi (2005, p. 12), o modo de circulação aponta para os trajetos dos dizeres, e estes são significativos para compreendermos os sentidos, já que "os sentidos são como se constituem, como se formulam e como circulam”.

Assim, consideramos que, no caso da Linguística no Brasil, para esse campo disciplinar-se e institucionalizar-se, foi necessário tanto a legitimação de quem produz ciência e a faz circular entre seus pares, quanto a legitimação via órgão Federal (Estado) e das Instituiçôes. Sobre a disciplinarização de um campo científico, podemos retomar os estudos realizados por Puech (2004) que propóe essa noção para "désigner le processus (historique) par lequel les propositions intellectuelles concernant le domaine considéré créent, reprennent et tentent de maîtriser la temporalité de leur développement" (PUECH, 2004, p. 125).

Para Scherer e Petri (2008), o campo disciplinar de uma ciência é afetado pela formação ideológica em que está inserido, afetando a história dos conceitos e a história cultural do disciplinar. Nesse sentido, a disciplinarização e a institucionalização do domínio da Linguística não está alheia à determinação ideológica e histórica que afeta a conjuntura em que se insere, pois "cada época tem suas convençóes, valores, visôes do mundo, formando um certo universo lingüístico-acadêmico, cujos elementos interdependentes

\footnotetext{
2 Podemos também citar a Revista Letras, que circulou nos anos de 1950, como sendo importante para a divulgação e legitimação do conhecimento linguístico, tal como aponta Paim (2015).
} 
mantêm entre si relaçóes associativas e funcionais, em constante processo de mudança" (SCHERER, 2005, p. 10).

\section{A Revista Brasileira de Filologia e os saberes da Linguística}

Considerando os aspectos levantados anteriormente, os estudos que vimos desenvolvendo ${ }^{3}$ tem por objetivo destacar a importância das revistas científicas para os estudos inseridos na perspectiva da História das Ideias Linguísticas. As revistas científicas, como as entendemos, não só contribuem para a comunicação científica, mas também para a produção do conhecimento, elas não se situam fora da história nem das relaçóes institucionais a que se vinculam e que individualizam os profissionais específicos que aí publicam (SCHNEIDERS, 2017).

Nessa reflexão, buscamos ressaltar, especificamente, a circulação dos saberes vinculados ao domínio da Linguística na Revista Brasileira de Filologia (RBF), a fim de explicitar as filiaçôes teóricas e de sentidos que se constituem e contribuem para o processo de legitimação e disciplinarização da Linguística no Brasil nesses espaços outros, que estáo fora do institucional, mas que sáo igualmente afetados por ele. A RBF circulou entre os anos de 1955 e 1961, no âmbito do contexto nacional brasileiro, tornando-se representativa para a época e "a mais completa e categorizada publicação do gênero no país” (ELIA, 1975, p. 158).

A fim de contextualizar a RBF, a mesma foi publicada pela Livraria Acadêmica, do Rio de Janeiro, editora importante da época que publicou muitas das obras filológicas do período. Como destacado em estudo anterior $^{4}$,

a revista tinha uma periodicidade semestral, com a publicaçáa de um vo-
lume por ano, sendo que o mesmo era composto por dois tomos, um por
semestre. A RBF teve seis volumes, totalizando a publicação de onze tomos
- faltando somente o Tomo II, do Vol. 6. Serafim da Silva Neto, além de
fundar, dirigiu a RBF até o ano de 1958, quando da publicação do volume
4. Os dois últimos volumes foram dirigidos pela comissáo formada por An-
tenor Nascentes, Ismael de Lima Coutinho, Sílvio Elia e Mattoso Câmara.

${ }^{3}$ Estudos vinculados ao projeto: Constituição, formulação e circulação do conhecimento linguístico no sul do Brasil.

${ }^{4}$ Realizamos um estudo mais detalhado sobre a importância e da estrutura da RBF no artigo

"A circulaçáo do conhecimento linguístico na Revista Brasileira de Filologia", disponível em:

<https://periodicos.ufsc.br/index.php/forum/issue/view/2581/showToc> 
No entanto, com a morte de seu fundador, em 1960, a revista passou a ter menos regularidade e foi publicada somente até 1961 (SCHNEIDERS, 2017 , p. 2760).

A RBF tornou-se nosso objeto de interesse devido ao fato de ser uma revista dita especializada de Filologia, como o seu nome nos apresenta. No entanto, ao adentrarmos aos conteúdos mobilizados em seu interior, observamos que a revista vai além dos assuntos da Filologia, constitui-se como um espaço para a circulação dos saberes linguísticos, ou seja, ela cumpre com o papel de divulgar a produção do conhecimento, no caso, sobre a língua/ linguagem. A RBF é estruturada da seguinte forma:

- 10: artigos de diferentes e importantes estudiosos que tratam de questôes da língua a partir de um olhar histórico e filológico;

- 20: seção denominada "Crônica Linguística", assinada por Joaquim Mattoso Câmara Jr.;

- 3o: espaço destinado a "Recensôes críticas e notas bibliográficas", a fim de divulgar estudos (tanto do domínio da Linguística quanto da Filologia) realizados a partir de um olhar crítico, no caso das "recensôes críticas", e de apresentar pontos relevantes sobre bibliografias recém-publicadas, como é o caso das "notas bibliográficas";

- 40: parte final destinada a "notícias e comentários" sobre eventos, reunióes, cursos, etc. realizados à época. Ainda, alguns tomos da revista finalizam com uma seção denominada In memoriam, com vistas a homenagear estudiosos que foram essenciais para o desenvolvimento das pesquisas linguísticas no Brasil.

Nessa reflexão, nosso interesse recai sobre a seção denominada "Crônica Linguística”, a fim de refletirmos acerca da importância dessa seção para a circulação e legitimação da Linguística. Buscamos destacar a contribuição das revistas científicas para a consolidação deste campo de conhecimento, enfatizando em especial a RBF por entendermos que esse objeto possibilita compreender "la dynamique du développement scientifique" (CHEVALIER, 1998, p. 68).

Para nós,

Une revue est un instrument d'action extrêmement souple qui, beaucoup plus subtilement qu'un livre, établit des liens entre des groupes de linguistes émetteurs (toute revue est collective, par définition), organisés par une direction et, d'autre part, des lecteurs et utilisateurs, souvent difficiles à cerner 
É, pois, tendo em vista esse entendimento sobre a revista, vista como um espaço coletivo, que aponta para as filiaçóes teóricas e de sentidos que buscamos produzir alguns gestos de interpretação sobre o funcionamento da seção 'Crônica Linguística'. As crônicas linguísticas são todas de autoria de Mattoso Câmara Jr., porém, nem todos os tomos e volumes da RBF as possuem, as que verificamos foram:

- Vol. 1, Tomo I: O sexto congresso internacional de linguistas

- Vol. 1, Tomo II: A conferência de indiana entre antropólogos e linguistas

- Vol. 2, Tomo I: Roman Jakobson

- Vol. 2, Tomo II: A Teoria Sintagmática de Mikus

Iniciamos nossas considerações pela designação dessa seção, a qual nos chama a atençáo pelo fato, como a própria definição de crônica sugere-nos, de ser um texto curto, destinado a destacar algo de ordem corriqueira, do cotidiano, circulando, sobretudo, nos meios de comunicação. Esse gênero, como sabemos, foi bastante difundindo a partir da publicação dos chamados Folhetins em meados do século XIX. Assim, entendemos que essa seção tem um papel fundamental no interior da RBF, visando justamente a fazer circular e divulgar o que estava acontecendo mundialmente sobre os estudos da Linguística.

Em um primeiro estudo realizado sobre a RBF, destacamos algumas consideraçóes a respeito do conteúdo de cada crônica, as quais valem a pena retomar (SCHNEIDERS, 2017, p. 2763-2764)

- Crônica 1 "O sexto congresso internacional de linguistas": traz um interessante panorama das 'Atas do Sexto Congresso Internacional de Linguistas', realizado em Paris, em 1948. As atas, segundo Mattoso Câmara Jr.,

permitem uma boa visão das correntes e tendências da linguística contemporânea, apesar da ausência de algumas figuras individuais de relevo e da de certos grupos nacionais, que por contingências da situação do mundo não

\footnotetext{
${ }^{5}$ Destacamos apenas de modo bastante sucinto o que cada crônica veicula para refletirmos sobre seu funcionamento. A RBF está disponível on line no site: $<$ http://www.josepereira.com. $\mathrm{br} / \mathrm{rbf}$.html>.
} 
Tal crônica faz-se relevante por colocar em circulação as discussôes sobre a Linguística que se vinham realizando, bem como o fato de referenciar importantes nomes desse domínio de saber.

- Crônica 2 "A conferência de indiana entre antropólogos e linguistas": trata-se de um breve relato sobre essa conferência, enfatizando, sobretudo, a relação entre a linguística e a antropologia cultural. Essa conferência foi realizada em julho de 1953, e Mattoso Câmara Jr. atenta para o fato de que a crônica não traz um relato do todo, omitindo alguns temas e debates "em detrimento de umas poucas idéias, aí ventiladas, que pareceram especialmente significativas [...] para os brasileiros" (In: RBF, Vol. 1, Tomo II, 1955, p. 195).

- Crônica 3 "Roman Jakobson": refere-se a uma homenagem a Jakobson, em comemoração aos seus sessenta anos. Nessa crônica, Mattoso Câmara Jr. traz uma síntese da "figura e da obra de Roman Jakobson nos quadros da linguística contemporânea", além de destacar o vínculo do pensamento científico deste estudioso com o de Troubetzkoy. As crônicas da RBF, tal como observamos nas duas primeiras, estavam destinadas a registrar eventos "significativos na linguística internacional", porém, nesta, como justifica Mattoso,

é justo que se aproveitem tôdas as oportunidades de ressaltar as contribuiçôes, para a consolidação, aprimoramento e renovaçáo da ciência da linguagem, trazidas, por linguistas do nosso tempo entre os quais aquêle de quem tratamos, é sem sombra de contestaçáo um dos mais valiosos (In: RBF, Vol. 2, Tomo I, 1956, p. 55).

Em nota de rodapé e a título de curiosidade, o autor destaca uma interessante informação: a possibilidade de Jakobson ter vindo para o Brasil, por convite da Universidade de São Paulo, antes de ter ido para os Estados Unidos. No entanto, isso não se efetivou "em virtude de empecilhos ulteriores”, nas palavras de Mattoso Câmara Jr.

- Crônica 4 "A Teoria Sintagmática de Mikus": discute a questão do sintagma, retomando, primeiramente, os pressupostos saussurianos, para, em seguida, trazer o estudo desenvolvido por Francis Mikus acerca dessa temática. Essa crônica, assim como a anterior, não apresenta o registro de eventos, mas uma questão teórica sob o ponto de vista da linguística mo- 
derna.

Pelas crônicas destacadas, observamos que as duas primeiras destinam-se a relatar os congressos internacionais realizados, bem como teóricos importantes para a reflexão da Linguística. Essa divulgação, para a produção do conhecimento, não deve ser vista como algo neutro, ao divulgar tais eventos, coloca-se em circulação, no contexto brasileiro, o que vem sendo discutido no âmbito mundial sobre o conhecimento linguístico. Orlandi (2002), em seu artigo "Ir ao congresso: fazer a história das ideias linguísticas?", ressalta justamente a importância dos eventos para o desenvolvimento do conhecimento linguístico. Para a autora, os congressos, "como toda institucionalização de relaçóes do saber, servem também, de forma pronunciada, a modos de legitimação das formas de saber e, muitas vezes, à tomada de posiçóes de poder universitário dos próprios intelectuais" (ORLANDI, 2002, p. 60).

No referido artigo, Orlandi faz uma discussão a partir de dois textos, um de Mattoso Câmara Jr. e outro de Jean-Claude Chevalier sobre os Congressos Internacionais de Linguística, refletindo sobre a posição-sujeito linguista que se constitui por meio da leitura que cada um realiza sobre os congressos. Trata-se de um interessante estudo que nos mostra a importância de Mattoso Câmara Jr. para a história da Linguística no Brasil, sem, no entanto, colocar-se nessa história:

\footnotetext{
Vemos que, sem se colocar no interior da história da linguística ao falar de seus congressos, vai colocando aos poucos nossa história como menção, quase causal. Isso me leva a dizer que ele se coloca na posição de quem é lingüista, de quem, com os outros, daqui e de "lá", faz essa história, mas não afirma sua posição como "participante", do ponto de vista dos Congressos. Ele está, com isso, preparando a vinda dos congressos brasileiros, nossa visibilidade como lingüistas (ORLANDI, 2002, p. 52).
}

Nesse sentido, as duas primeiras crônicas têm, para nós, uma função essencial ao divulgar tais congressos internacionais: "O sexto congresso internacional de linguistas" e "A conferência de indiana entre antropólogos e linguistas", uma vez que contribuem sobremaneira para a circulação e a legitimação dos saberes vinculados à Linguística. Tais crônicas, ao estarem publicadas no interior de uma revista de Filologia, apontam para um funcionamento peculiar desse periódico, o fato de trazer para seu interior, na expressão de Sériot (1999), l'air du temps.

Compreender o air du temps, segundo Sériot (1999, p. 27), é 
de rapporter une théorie linguistique à ses conditions historiques de production, d'évaluer les interactions existant entre des théories voisines ou entre des champs discursifs contemporains, de restituer l'air du temps et l'air $d u$ lieu dans lequel um dispositif de pensée s'inscrit.

Esse air du temps também traz para a questáo as relaçóes entre os teóricos que se estabeleceram nessa conjuntura em específico que nos interessa. As filiaçóes teóricas nos são igualmente relevantes, visto que, com elas, podemos observar como as redes de filiaçóes de sentidos vão estabelecendo-se e contribuindo para a legitimação do conhecimento linguístico. A primeira filiação a ser destacada é a relação estabelecida entre Serafim da Silva Neto, que é também o editor da RBF, e Mattoso Câmara Jr.

Essa relação entre os teóricos é interessante, pois vemos que, embora Mattoso Câmara Jr. tenha tido um lugar periférico junto aos seus pares e em sua carreira acadêmica, por tentar introduzir novos preceitos, rompendo, de certa forma, com a tradição filológica da época, houve um acolhimento de suas ideias em "[...] periódicos em que também publicavam os filólogos. Portanto, se a sua posição no grupo não foi das mais destacadas, não foi também o que se pode chamar com exatidão de 'marginal'" (COELHO, 1998, p. 101).

Como sabemos por meio dos estudos historiográficos sobre os estudos linguísticos, Serafim da Silva Neto teve, desde o início de sua carreira, um lugar reconhecido junto à comunidade filológica da época, bem diferente do que aconteceu com Mattoso Câmara Jr.. Coelho (1998, p. 172) destaca que "as 'ideias' de Silva Neto foram interpretadas como 'boas' neste contexto e o mesmo não ocorreu com as de Mattoso". Assim,

Mattoso Câmara, com ideias que posteriormente foram reconhecidas como 'boas', adequadas, não alcançou o mesmo destaque, talvez por não ter marcado tấo claramente uma postura continuísta em relação à tradição filológica luso-brasileira, como o fez Silva Neto. Tradição que, afinal, era aquela cujos representantes estiveram à frente dos processos de 'organização' - da área de estudos e das instituiçóes - que tão acentuadamente caracterizaram o período na história dos estudos sobre a linguagem no Brasil (COELHO, 1998, p. 174).

O que observamos é, portanto, que Mattoso, mesmo não possuindo um lugar institucional reconhecido, ele esteve inserido junto ao grupo de es- 
tudiosos reconhecidos da época e inserido nas revistas científicas, por exemplo. Dentre os estudiosos que se destacaram no desenvolvimento inicial da Linguística, sendo considerados legitimados e legitimadores na relaçáo com a reflexáo linguística, podemos citar: Serafim da Silva Neto, Joaquim Mattoso Câmara Jr., Capistrano de Abreu, Said Ali, Antenor Nascentes, Theodoro Sampaio e Sousa da Silveira (LAGAZZI-RODRIGUES, 2002).

Um outro aspecto a ser ressaltado é a ênfase de Mattoso Câmara Jr., na segunda crônica, na relação entre a linguística e a antropologia. Essa ênfase justifica-se, pois, como sabemos, Mattoso Câmara Jr., nos anos de 1940, trabalhou voluntariamente no Museu Nacional, mantendo um estreito contato com antropólogos. Desse contato resultou sua viagem para os Estados Unidos (1943-1944) e sua relação teórica com Roman Jakobson e Louis Gray (GUIMARÂES, 2004).

As filiaçóes que vão se estabelecendo se reforçam na terceira crônica "Roman Jakobson", a qual se refere a uma homenagem a Jakobson, em comemoraçáo aos seus sessenta anos. Não é por acaso que Mattoso Câmara Jr. dedica uma crônica para exaltar a obra e a figura de Roman Jakobson, é devido, sobretudo, à relação teórica, e também pessoal, estabelecida entre os dois estudiosos. Essa relaçáo pode ser observada por meio das constantes correspondências trocadas entre ambos ${ }^{6}$, nas quais, inclusive, Mattoso Câmara Jr. comenta sobre a publicação dessa crônica. Além disso, podemos dizer que os estudos linguísticos propostos por Mattoso Câmara Jr. foram afetados por essa relação, bem como os estudos linguísticos brasileiros de maneira geral tiveram essa influência de Jakobson pela relevância que o mesmo teve à época.

No que se refere à quarta crônica "A Teoria Sintagmática de Mikus", ao contrário das outras, nesta há uma discussão mais teórica, voltada à problemática do sintagma, retomando, primeiramente, os pressupostos saussurianos, para, em seguida, trazer o estudo desenvolvido por Francis Mikus acerca dessa temática. Tal discussão torna-se relevante na medida em que traz esses aspectos sob o ponto de vista da linguística moderna, buscando marcar a contribuição desses preceitos na discussão sobre a língua, como é o caso do sintagma, saindo do paradigma gramatical e filológico, como era a tradição no contexto brasileiro.

Retomar tais aspectos, para nós que nos inserimos no campo da HIL, são fundamentais, pois todas as relaçôes que vão se constituindo irão de-

${ }^{6}$ As correspondências a que nos referimos estão disponíveis na Biblioteca Mattoso Câmara, em Petrópolis, Rio de Janeiro. 
terminar as condições de produção do conhecimento linguístico no Brasil. A produção do conhecimento configura-se enquanto uma prática social, sendo o contexto sócio-histórico e ideológico determinante para a sua produção, afetando as condiçóes de produção do discurso. Pêcheux (2009 [1975]) destaca que a produção do conhecimento científico é resultante de um processo histórico determinado, enfatizando que as "ideias científicas" não se desvinculam da história, são afetadas historicamente e estão em relação à(s) ideologia(s) de certa conjuntura. Ao compreendermos as condiçốes de produção do discurso, poderemos definir tanto o modo como se entende determinado domínio de saber quanto delimitar o que quer que se recorte, para ser colocado em circulaçáo e divulgaçáo.

Ou seja, compreender as filiaçôes teóricas e de sentidos que se estabelecem quando refletimos sobre a produção do conhecimento é, conforme Chiss \& Puech (1999),

proclamer des filiations ou des affiliations, c'est organiser un champ de savoir
homogène par un certain agencement de la mémoire. Définir un objet pro-
pre dans ce champ homogène, c'est indexer, identifier, décrire les principaux
domaines de la discipline où l'objet trouve sa place légitime. Fixer des tâches
programmatiques, c'est compléter, par la dimension projective, la cohérence
rétrospective et synchronique de la discipline. Le point de vue disciplinai-
re, par quelque côté qu'on l'envisage, nous confronte donc à la dimension
temporelle (retrospection, délimitation synchronique, projection) d'une re-
présentation du savoir (CHISS \& PUECH, 1999, p. 16).

Assim, a produção do conhecimento não é indiferente à conjuntura em que se inscreve, é condicionada por uma série de fatores que a afetam e a configuram. As crônicas linguísticas da RBF, tal como observamos, nos permitem compreender que,

mesmo sendo uma revista científica dita especializada, em sua constituiçáo, há a presença de outros domínios de saber, como é o caso da Linguística, contribuindo, portanto, para a circulação e, de certa forma, para a institucionalizaçấo desse domínio no contexto brasileiro (SCHNEIDERS, 2017, p. 2766). 


\section{Consideraçóes finais}

Ao refletirmos sobre as filiaçóes teóricas e de sentidos que se constituem no interior da RBF, por meio da publicação da seçáo 'Crônica linguística', todas de autoria de Mattoso Câmara Jr., compreendemos que tais filiaçôes contribuem para explicitarmos o processo de legitimação da Linguística no Brasil. Por meio das crônicas, podemos dizer que há dois funcionamentos, um que se vincula à importância dos congressos para a legitimaçáo dos saberes da Linguística, os quais, segundo Orlandi (2002, p. 62),

\footnotetext{
na representação que a ciência da linguagem dá de si, [...] são um lugar de traçar sua fisionomia. Mas como em todo processo de disciplinarização, náo é só o que fica dentro desse contorno que define a sua história. O discurso do conhecimento, como qualquer outro, está em movimento e não se deixa enclausurar, desenhando seus meandros no fluxo do saber.
}

Já o outro funcionamento refere-se às relaçôes teóricas estabelecidas, constituindo uma rede de filiaçóes que representam o air du temps, determinando, de certo modo, os saberes que são postos em circulação, o que se publica e quem publica nesses espaços como é o das revistas científicas. Assim, consideramos que esses dois funcionamentos só podem ser observados por meio da relaçáo entre a circulaçáo e a legitimação do conhecimento, contribuindo para a institucionalização e disciplinarização dos saberes na Linguística no Brasil. 


\section{Referências}

ALTMAN, C. A pesquisa lingüística no Brasil (1968-1988). 2. ed. São Paulo: Humanitas, 2004.

AUROUX, S. A revolução tecnológica da gramatizaçáo. Trad. Eni P. Orlandi. Campinas: UNICAMP, 1992.

COELHO, O. F. Serafim da Silva Neto (1917-1960) e a Filologia Brasileira. Um Ensaio Historiográfico sobre o Papel da Liderança na Articulação de um Paradigma em Ciência da Linguagem. 1998. 184f. Dissertação de Mestrado (Mestrado em Letras) - Faculdade de Filosofia, Letras e Ciências Humanas da Universidade de São Paulo. São Paulo, 1998.

CHEVALIER, J.-C. Places dês revues dans La constituition d'une iscipline; La Linguistique Française (1945-1997). Langue Française 117. Paris: Larouse, p. 68-71, 1998.

CHISS, J-L.; PUECH, C. Le langage et ses disciplines (XIX-XX siècles). Paris, Bruxelles: De Boeck \& Larcier s.a, 1999.

ELIA, S. Ensaios de filologia e lingüística. 2. ed. Rio de Janeiro: Grifos, 1975.

GUIMARÃES, E. História da Semântica: Sujeito, Sentido e Gramática no Brasil. Campinas: Pontes, 2004.

LAGAZZI-RODRIGUES, S. A língua portuguesa no processo de institucionalização da lingüística. In: ORLANDI, E.; GUIMARÃES, E. (orgs.). Institucionalizaçáo dos estudos da linguagem: a disciplinarização das idéias lingüísticas. Campinas, Pontes, 2002. p.13-22.

O político na Lingüística: Processos de representação, legitimação e institucionalização. In: ORLANDI, E.; GUIMARÃES, E. (orgs.). Política Lingüística no Brasil. Campinas: Pontes, 2007. p. 11-18. 
ORLANDI, E. Ir ao congresso: fazer a história das idéias linguísticas? In: GUIMARÃES, E; ORLANDI, E. (orgs.). Institucionalizaçáo dos estudos da linguagem: a disciplinarização das idéias lingüísticas. Campinas: Pontes, 2002. p. 41-62.

Discurso e Texto: formulação e circulação de sentidos. Campinas: Pontes, 2005.

PAIM, Z. V. O texto de apresentação nas revistas acadêmicas: da singularização a inscrição no lugar de uma falta. Interfaces, vol. 6, n. 3, dez., p. 88-100, 2015.

PÊCHEUX, M. Semântica e discurso: uma crítica à afirmação do óbvio. 4. ed. brasileira. Trad. Eni Orlandi et al., SP: Campinas, Editora da Unicamp, 2009 [1975].

PUECH, C. Antinomies (V. Henry) et Dichotomies (F. De Saussure) l'idée d'une - science double - dans la linguistique générale de la fin du XIX siècle. Linguistique et partages disciplinaires à la charnières des XIX et XX siècles: Victor Henry (1850-1907). Louvain, Paris: Editions Peeters, Bibliothèque de l'Information Grammaticale, n. 55, p. 125-150, 2004.

Revista Brasileira de Filologia, Vol. 1, Tomo I, junho, 1955.

Revista Brasileira de Filologia, Vol. 1, Tomo II, dezembro, 1955.

Revista Brasileira de Filologia, Vol. 2, Tomo I, junho, 1956.

Revista Brasileira de Filologia, Vol. 2, Tomo II, dezembro, 1956.

RODRIGUES, A. D. A Obra Científica de Mattoso Câmara Jr. Estudos da Língua(gem). Mattoso Câmara e os Estudos Linguísticos no Brasil, Vitória da Conquista, vol. 2, n. 1, p. 11-28, dez., 2005. 
SCHERER, A. E. Lingüística no sul: estudos das idéias e organização da memória. In: GUIMARÃES, E.; BRUM DE PAULA, M. (orgs.). Sentido e memória. Campinas, Editora Pontes, p. 9-26, 2005.

- Dos domínios e das fronteiras: o lugar fora do lugar em outro e mesmo lugar. In: SARGENTINI, V.; GREGOLIN, M. do R. (org.) Análise do Discurso: heranças, métodos e objetos. Sáo Carlos: Clara Luz, 2008. p.131-141.

; PETRI, V. Discours ou discourse: invention, configuration, transmission et disciplinarisation au Brésil. In: Revista Letras: Língua, Sujeito e História, no 37, v. 18, n.2, jul./dez., p. 9-18, 2008.

SCHNEIDERS, C. M. Serafim da Silva Neto: entre a constituição e a circulação do conhecimento linguístico. 2014. 218f. Tese (doutorado) - Universidade Federal de Santa Maria, Centro de Artes e Letras, Programa de Pós-Graduação em Letras. Santa Maria, RS, 2014.

A circulação do conhecimento linguístico na Revista Brasileira de Filologia. Fórum linguístico, Florianópolis, v. 14, n. 4, out,/dez., p. 27562770, 2017.

SÉRIOT, Patrick. Structure et totalité: les origines intellectuelles du structuralisme en Europe Centrale et Orientale. Paris: Presses Universitaires de France, 1999.

Recebido: 15/07/2018

Aceito: 01/12/2018

DOI: $10.5902 / 2179219436814$ 